\title{
Effectiveness of highly active antiretroviral therapy administered by general practitioners in rural South Africa
}

\author{
R. E. Barth • J. T. M. van der Meer • \\ A. I. M. Hoepelman • P. A. Schrooders • \\ D. A. van de Vijver • S. P. M. Geelen • H. A. Tempelman
}

Received: 20 November 2007 / Accepted: 15 April 2008/Published online: 16 July 2008

(C) The Author(s) 2008

\begin{abstract}
The purpose of this study was to assess the oneyear efficacy of highly active antiretroviral therapy (HAART) administered by general practitioners in a primary care community clinic in rural South Africa. We performed an observational cohort study of 675 treatmentnaïve human immunodeficiency virus (HIV)-infected patients (including 66 children) who began HAART at least 12 months prior to the data analyses. Throughout treatment, the CD4+ T-cell count (percentage of CD4+ Tcells in children) and plasma HIV-RNA level were determined and the patient's weight was recorded. The
\end{abstract}

R. E. Barth · A. I. M. Hoepelman ( $\square)$

Department of Internal Medicine and Infectious Diseases and the Eijkman-Winkler Institute for Medical Microbiology and Infectious Diseases, University Medical Centre Utrecht, Heidelberglaan 100,

3584 CX Utrecht, The Netherlands

e-mail: I.M.Hoepelman@umcutrecht.nl

J. T. M. van der Meer

Department of Internal Medicine, Subdivision of Infectious Diseases, Tropical Medicine and AIDS, Academic Medical Centre, University of Amsterdam,

Meibergdreef 9, Postbus 22660, 1100 DD Amsterdam,

The Netherlands

P. A. Schrooders $\cdot$ H. A. Tempelman

Ndlovu Medical Centre,

Elandsdoorn, Mpumalanga, South Africa

D. A. van de Vijver

Department of Virology, University Medical Centre Utrecht, Heidelberglaan 100,

3584 CX Utrecht, The Netherlands

\section{S. P. M. Geelen}

Department of Pediatric Infectious Diseases,

University Medical Centre Utrecht and PharmAccess Foundation,

Amsterdam, The Netherlands primary outcome was mortality. Secondary outcomes were viral suppression, immunological response, and weight gain. One year after the start of HAART, 100 of the 675 (15\%) patients were lost to follow-up and 119 patients (18\%), including six children, died. Mortality was highest during the first few months of treatment. Based on an ontreatment analysis at one year after the start of therapy, $83 \%$ of adults and $71 \%$ of children had a viral load $<400$ copies/ $\mathrm{ml}$; the viral load was $<50$ copies $/ \mathrm{ml}$ in $70 \%$ of adults and $61 \%$ of children. At one year, the mean CD4+ T-cell count in adults had increased by $236 / \mathrm{mm}^{3}$, and the mean body mass index (BMI) had increased by $3.5 \mathrm{~kg} / \mathrm{m}^{2}$. In children, the mean $\mathrm{CD} 4 \%$ had increased by 17.6. A low Karnofsky score and a low baseline CD4+ T-cell count were independently associated with death. In addition to these factors, a low baseline BMI and gender were predictive of a poor immunological outcome. Our study shows that adequately monitored HIV/acquired immunodeficiency syndrome (AIDS) care administered by general practitioners and their staff is feasible and leads to good results in a rural, primary care center in sub-Saharan Africa. In order to achieve even better results, early mortality should be reduced and efforts should be made to start HAART earlier.

\section{Introduction}

Highly active antiretroviral therapy (HAART) is acknowledged worldwide as the standard of care for people with human immunodeficiency virus/acquired immunodeficiency syndrome (HIV/AIDS) [1-3]. It decreases plasma HIVRNA levels, increases CD4+ T-cell counts, decreases morbidity, and prolongs survival in HIV-infected patients $[4,5]$. Several studies have shown that HAART can be applied with the same efficacy in developing and developed 
countries [6-11]. However, concerns about the lack of infrastructure, irregular medication supply, and poor adherence has led to pessimism about the feasibility of HAART programs in resource-constrained settings. Figures from the World Health Organization (WHO) show that only $17 \%$ of people who need HAART in sub-Saharan Africa actually receive it [12]. The failure of initial antiretroviral regimens and the emergence of widespread antiretroviral drug resistance, which would reduce the long-term durability of HAART in developing countries, is a serious concern.

The implementation of HAART in rural areas of resourcelimited countries can be hazardous. This observational study reports on the one-year efficacy of HAART in a sub-Saharan, rural setting in 675 consecutive patients who were initiated antiretroviral therapy from September 2003 through April 2006. The patients were treated in a primary care setting and the treatment was administered and monitored by general practitioners. In addition to clinical and immunological data, longitudinal viral load testing was also performed.

\section{Methods}

Site and patients

Elandsdoorn is a township with an estimated population of 40,000. It is situated in a poor, rural area in Mpumalanga, a province in the northeast of the Republic of South Africa. AIDS is the leading cause of death in adults in South Africa, and it is estimated that about $48 \%$ of deaths are related to HIV [13]. In a Mpumalanga-based study, the HIV prevalence among adults aged 15 to 49 years was $23.1 \%$ [14]. Among antenatal clinic attendees, HIV prevalence was $30.8 \%$ [15].

The Ndlovu Medical Centre is a non-governmental organization in Elandsdoorn (http://www.elandsdoorn.com/) that provides "paid for service" primary health care, as well as prevention-, tuberculosis-, and HIV/AIDS-programs which are donor-funded and free of charge for the patient.

During the study period, five general practitioners were in charge of running the outpatient clinic. The clinic has a maternity ward with 16 beds. Some of these beds can also be used for HIV/AIDS patients. The clinic is equipped with $\mathrm{X}$-ray and ultrasound equipment, a pharmacy, and a laboratory with facilities to perform CD4+ T-cell counts, plasma HIV-RNA analysis, full blood counts, and blood chemistry investigations. In 2003, a privately subsidized program for the provision of HAART was initiated.

In accordance with the WHO guidelines, adults were eligible for antiretroviral therapy if they had a WHO stage IV AIDS-defining illness, irrespective of their CD4+ T-cell count, or if their CD4+ T-cell count was below $200 / \mathrm{mm}^{3}$, irrespective of their clinical stage $[1,2]$. Children were eligible if they had a WHO stage C disease or a CD4 percentage of less than $15[1,3]$.

Patients could enroll in the program if they lived within a $25-\mathrm{km}$ radius of the clinic. To optimize adherence, a number of psychosocial conditions were established for inclusion: (1) disclosure of HIV status to at least one relative or friend who had to accompany the patient to the clinic when he/she came for information and counseling; (2) a relative or friend willing to support the patient in treatment adherence (family and friends assisted treatment adherence; FAST); and (3) demonstrated reliability, i.e., the patient had attended three or more scheduled visits to the clinic over a three-month period. The final decision to treat was ascertained by a multidisciplinary team including both community members and the caregiver. During HAART, the patients were seen by a doctor and counselor every two weeks for the first two months and monthly thereafter. The counselors completed questionnaires on employment, means of income, education, and household structures when the patients entered the program.

Antiretroviral therapy was in accordance with the national guidelines [16]. Unless contraindicated, all patients (children and adults) started therapy with stavudine (d4T, $40 \mathrm{mg}$ bid or $30 \mathrm{mg}$ bid if their weight was less than $60 \mathrm{~kg}$ ), lamivudine (3TC, $150 \mathrm{mg}$ bid), and efavirenz (EFV, $600 \mathrm{mg} \mathrm{qd}$ ) or nevirapin (NVP, $200 \mathrm{mg}$ bid). All drugs were administered separately, as triomune was not available. Later, during the inclusion period, patients often began receiving Combivir combined with either nevirapin or efavirenz. Young children were given syrups and older children were given tablets. The dosage depended on the child's weight.

For second-line treatment, non-nucleoside reverse transcriptase inhibitors (NNRTIs) could be switched to the protease inhibitors (PIs) lopinavir/ritonavir. The efavirenz dose was not adjusted during treatment with rifampin. HIVinfected patients with pulmonary tuberculosis and a CD4+ T-cell count higher than $200 / \mathrm{mm}^{3}$ were treated for tuberculosis, and antiretroviral therapy was deferred until they met the WHO criteria. In patients with tuberculosis and a CD4+ T-cell count of less than $200 / \mathrm{mm}^{3}$, antiretroviral therapy was initiated after the completion of two months of tuberculosis therapy or, simultaneously, depending on the clinical status of the patient.

The counselors monitored adherence to HAART during the patients' visits to the clinic and during home visits. If necessary, the patients received funds to cover the cost of transport to the clinic and food parcels.

Data collection

Data were retrospectively collected from the medical charts. Patients entered the program from September 2003 through 
April 2006, by definition, at least 12 months before the data analyses, and were all treatment-naïve when starting HAART. The clinic also treats pregnant women according to the prevention of mother-to-child transmission (pMTCT) protocol. Data from the pMTCT program were not included in this study, as inclusion of the pMTCT recipients would make the study population more heterogeneous.

Adults' body mass indices (BMI, weight $/$ height $^{2}$ ) and children's weights were recorded during each visit. The Karnofsky performance score and the WHO staging system were used to establish the patient's clinical condition when HAART was initiated. At baseline, the CD4+ T-cell count (FACSCount system, Becton Dickinson Biosciences, San Jose, CA), the plasma HIV-RNA level (System 340 bDNA analyzer, Bayer AG, Leverkusen, Germany), and a full blood count were measured, and at 6 , $12,24,36$, and 52 weeks, the plasma HIV-RNA level, CD4+ T-cell count (CD4\% in children), full blood count, and alanine aminotransferase (ALT), aspartate aminotransferase (AST), creatinin, urea, and amylase concentrations were measured.

\section{Statistical analysis}

The data were analyzed on both an intention-to-treat (ITT) and an on-treatment (OT) basis. The primary endpoint was mortality from all causes during the first year after starting HAART. Secondary endpoints were the proportion of patients with a viral load of less than 50 and less than 400 copies $/ \mathrm{ml}$, good immunological response as defined by a CD4+ T-cell count higher than $200 / \mathrm{mm}^{3}$ or a CD4\% of 15 or higher in children, and an increase in BMI or weight. We ignored treatment changes and interruptions.

To define predictors of treatment efficacy, we compared the outcome (survival and immunological response) of adult patients who presented a poor clinical condition at baseline, as defined by a BMI in the lowest quartile, a Karnofsky score of 50 or less, and a CD4+ T-cell count of $50 / \mathrm{mm}^{3}$ or less, with that of patients who were in better condition.

Continuous data were compared with Student's $t$-test or the paired $t$-test, as appropriate. Proportions were compared with the $\chi^{2}$ test, and data that were not normally distributed were analyzed via the Mann-Whitney $U$-test or Wilcoxon's test. Kaplan-Meier survival analyses were used to estimate the time from the initiation of antiretroviral therapy to viral suppression and good immunologic response. Odds ratios were calculated using logistic regression analysis. The Cox proportional-hazards model was used to identify independent predictors of the endpoints. To this end, a multivariate analysis was performed for all variables that were significant $(p<0.10)$ in the univariate analysis.

\section{Results}

\section{Patient characteristics}

Between September 2003 and May 2006, the Ndlovu Medical Center provided HIV voluntary counseling and testing (VCT) to 5,226 patients, of whom 2,442 (47\%) were tested as HIV seropositive (Fig. 1). Of these, 675 (28\%) started antiretroviral therapy and were included in our analysis; 609 (90\%) were adults (age range 16 to 73 years) and $66(10 \%)$ were children (age range eight months to 11 years). Fifty-four percent of the adults and $77 \%$ of the children were also treated for tuberculosis.

The baseline patient characteristics and initial antiretroviral therapy regimens of the adults and children are summarized in Table 1. At presentation, 32 patients $(5 \%)$ were too weak to stand and a BMI could not be calculated. In the remaining patients, the median BMI was significantly lower in men $\left(18.6 \mathrm{~kg} / \mathrm{m}^{2}\right)$ than in women $\left(20.3 \mathrm{~kg} / \mathrm{m}^{2}\right.$, $p<0.01)$. There was also a significant difference in the median CD4+ T-cell counts between men and women of $54 / \mathrm{mm}^{3}$ and $74 / \mathrm{mm}^{3}$, respectively $(p=0.02)$. The median weight of the children at baseline was $13.8 \mathrm{~kg}$. The low average socio-economic status is shown by the high unemployment rate among participants and widespread dependency on government grants.

\section{Patient outcome}

At 12 months after HAART initiation, 407 of 609 adults (67\%) and 49 of 66 children (74\%) were alive and in care. Eighty-nine adults (15\%) and 11 children (17\%) were lost to follow-up. There was a statistically significant difference in the baseline CD4+ T-cell counts between patients who were lost to follow-up and those who were not; $86 / \mathrm{mm}^{3}$

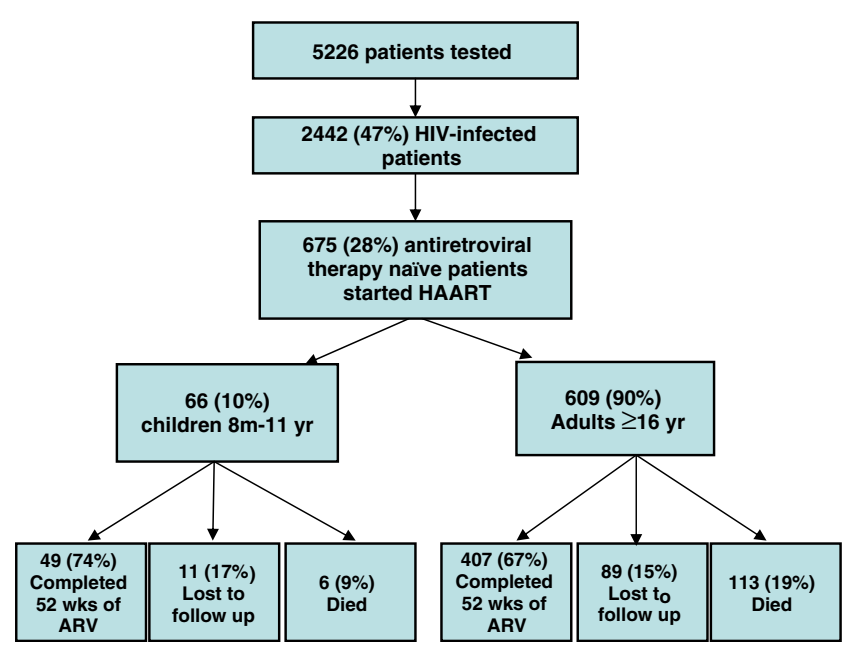

Fig. 1 Cohort profile. $H A A R T=$ highly active antiretroviral therapy; $m=$ months; $y r=$ years; $A R V=$ antiretroviral therapy 
Table 1 Patients' characteristics

Characteristic

Age (SD)

Female sex, $n(\%)$

TB treatment, $n(\%)$

- No TB treatment

- TB treatment prior to HAART

- TB treatment during HAART

BMI, median (inter-quartile range)

- Total adult population

- Men

- Women

Weight, median (range) $(\mathrm{kg})$

WHO stage, $n(\%)$

- WHO 1

- WHO 2

- WHO 3

- WHO 4

- Missing

Karnofsky score, $n(\%)$

$-\leq 50$

$->50$

- Missing

CD4 T-cell count, median (range) (cell count $/ \mathrm{mm}^{3}$ )

- Total adult population

- Men

- Women

CD4 percentage, median (range)

$10 \log$ (baseline viral load)

- Median (range)

ARV regimen, $n(\%)$

Lamivudine/stavudine/efavirenz

Lamivudine/stavudine/nevirapin

Lamivudine/zidovudine/efavirenz

Lamivudine/zidovudine/nevirapin

DDI/stavudine/efavirenz

Combivir/efavirenz

Combivir/nevirapin

*Unemployment rate, $n(\%)$

*Means of income

- None

- Employment

- Money from family member

- Grant

- Missing

*Living with a partner, $n(\%)$

* Number of people in household

- Median (range)

*Education

- None

- Grade 1 to 6

- Grade 7 to 12

- Third level

- Missing
Adults $(n=609)$

Children $(n=66)$

34.9 years $(9.0)$

431 (70.8)

57 months (31.3)

$33(50.0)$

$281(46.1)$

15 (22.7)

$152(25.0)$

$26(39.4)$

$176(28.9)$

$25(37.9)$

$19.6(17.2-22.6)$

$18.6(16.8-21.5)$

20.3 (17.6-23.4)

51 (24-94)

$13.8(5.5-23,3)$

59 (9.7)

63 (10.3)

$375(61.6)$

$106(17.4)$

$6(1.0)$

47 (7.7)

$560(92.0)$

$2(0.3)$

$67(1-466)$

$54(1-466)$

74 (1-379)

$5.0(1.4-5.9)$

$0.6(0.1-29.8)$

$5.1(3.0-5.7)$

257 (42.2)

201 (33.0)

$86(14.1)$

$39(6.4)$

$2(0.3)$

$22(3.6)$

$2(0.3)$

428 (75.8)

$144(25.5)$

135 (23.9)

$152(26.9)$

$132(23.4)$

$2(0.4)$

$278(49.2)$

$6(1-16)$

$51(8.4)$

76 (12.5)

$425(69.8)$

7 (1.2)

48 (7.9)

$\mathrm{TB}=$ tuberculosis

$\mathrm{ARV}=$ antiretroviral therapy

DDI=didanosine

*=socio-demographic data were known for 565 of 609 adults $(93 \%)$ 
versus $64 / \mathrm{mm}^{3}$, respectively $(p=0.05$ ). Other baseline characteristics were comparable between these two groups (data not shown). One hundred and thirteen adults $(19 \%$, Table 2) and six children (9\%) died. Of the 113 adult deaths, $49(43 \%)$ occurred within the first month after the initiation of HAART and $78(69 \%)$ occurred within the first two months. Three of the six children passed away during the first month of HAART.

As most patients died at home, the actual cause of death was often unknown.

There was no statistically significant difference in survival between patients who received tuberculosis treatment and those who did not $(p=0.7)$.

Viral load, CD4+ T-cell response, and BMI in adults

No blood samples were available after the baseline sample in 81 of the 609 (13\%) adults: 49/81 died and 32/81 were lost to follow-up before a second sample could be drawn. For the remaining 528 patients, on-treatment blood samples were available as well. A plasma HIV-RNA level lower than 400 copies $/ \mathrm{ml}$ in at least one of those blood samples was seen in 494 of these 528 (94\%) patients, and a plasma HIV-RNA level lower than 50 copies/ml was registered in 439 of 528 patients (83\%, Fig. 2).

Longitudinal follow-up of the patients who achieved viral suppression showed that plasma HIV-RNA levels remained lower than 400 copies $/ \mathrm{ml}$ in 400 of $494(81 \%)$ patients, and lower than 50 copies $/ \mathrm{ml}$ in 316 of 439 patients (72\%). Virological failure (plasma HIV-RNA $>1,000$ copies $/ \mathrm{ml}$ ) occurred in 51 patients $(10 \%)$. No further data after the initial viral suppression were available for $43(9 \%)$ patients (Fig. 3).

At one-year follow-up, the plasma HIV-RNA level was lower than 400 copies $/ \mathrm{ml}$ in 336 patients $(336 / 609$ ITT $=55 \%, 336 / 407$ OT $=83 \%$ ) and lower than 50 copies/ $\mathrm{ml}$ in 283 patients $(283 / 609 \mathrm{ITT}=46 \%, 283 / 407 \mathrm{OT}=70 \%)$.

The mean increase in the CD4+ T-cell counts was 168/ $\mathrm{mm}^{3}(95 \%$ CI: $156-179, p<0.001)$ at week 24 and $236 /$ $\mathrm{mm}^{3}$ (95\% CI: $\left.220-252, p<0.001\right)$ at week 52, resulting in

Table 2 Mortality in adults according to CD4 count at baseline

\begin{tabular}{lll}
\hline CD4 & $n$ & Died \\
\hline $0-50$ & 256 & $70(27 \%)$ \\
$51-100$ & 124 & $14(11 \%)$ \\
$101-200$ & 188 & $26(14 \%)$ \\
$>200$ & 38 & $3(8 \%)$ \\
Total & 606 & 113 \\
\hline
\end{tabular}

CD4=CD4 + T-cell count at baseline (cell count $/ \mathrm{mm}^{3}$ ) $n=$ number of patients who started antiretroviral therapy NB: CD4 count at baseline was unknown for three patients; these patients did not die

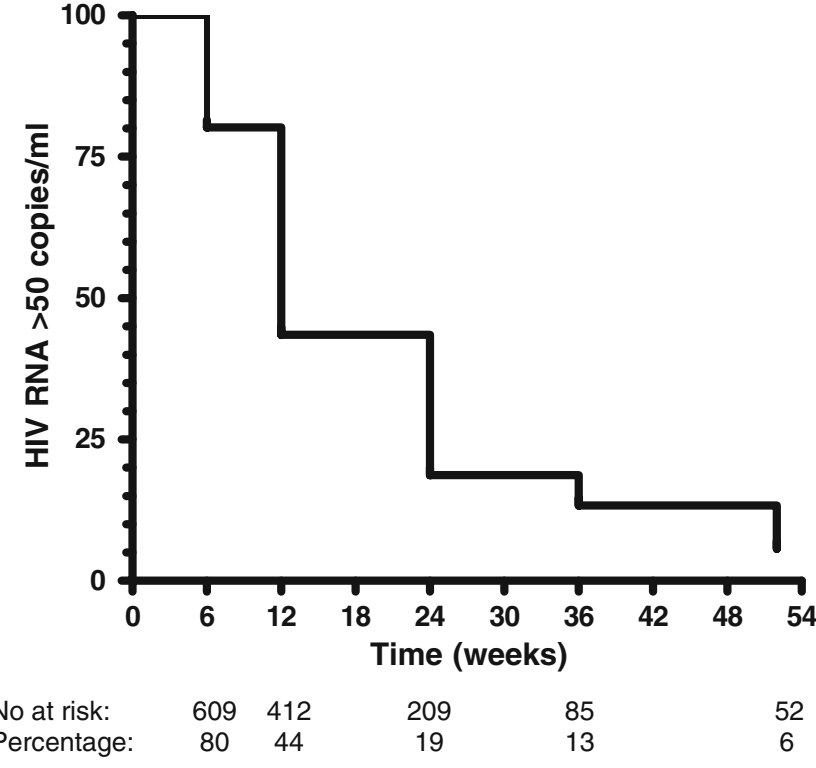

Fig. 2 Kaplan-Meier estimate of the proportion of adult patients with a plasma HIV-RNA level of more than 50 copies/ml during antiretroviral therapy

a median CD4+ T-cell count of 297/ $/ \mathrm{mm}^{3}$ (IQR 195-421/ $\mathrm{mm}^{3}$ ). Sixty-one percent of adults had a good immunological response (CD4 T-cell count $>200 / \mathrm{mm}^{3}$ ) at week 24 and $74 \%$ at week 52 (on-treatment analysis).

The mean BMI had increased by $2.4 \mathrm{~kg} / \mathrm{m}^{2}(p<0.001)$ at week 24 and by $3.5 \mathrm{~kg} / \mathrm{m}^{2}(p<0.001)$ at week 52 , resulting in a median BMI of $23.4 \mathrm{~kg} / \mathrm{m}^{2}$ at week 52 .

Viral load, CD4+ T-cell response, and weight in children

Apart from the seven children who either died or were lost to follow-up before week six, a plasma HIV-RNA level lower than 400 copies $/ \mathrm{ml}$ was registered at some time during therapy in all 59 children, and a level lower than 50

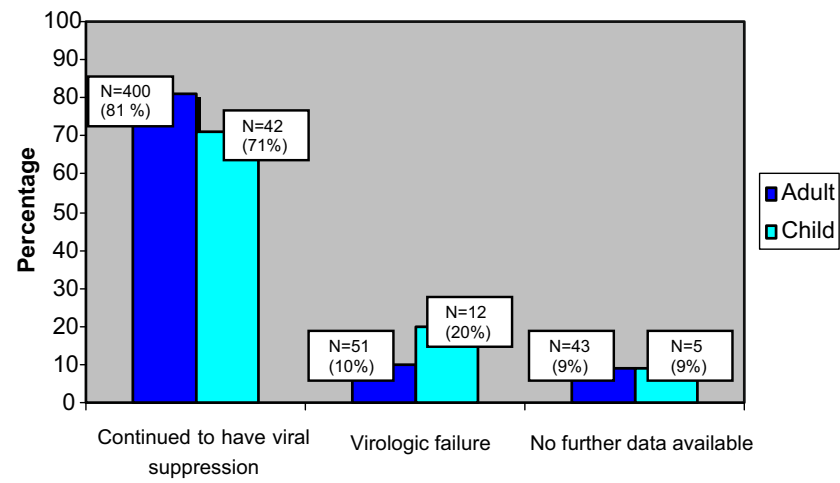

Fig. 3 Virological data in adults and children after reaching a plasma HIV-RNA level $\leq 400$ copies $/ \mathrm{ml}$. Continued to have viral suppression is defined as having a plasma HIV-RNA levelbelow 50 copies $/ \mathrm{ml}$ during successive measurements. The probability of experiencing virological failure was significantly higher in children than in adults $(p<0.025)$ 
copies/ml was registered in 52/59 children (88\%). Plasma HIV-RNA levels remained under 400 copies $/ \mathrm{ml}$ during consecutive tests in $42 / 59$ children (71\%); $33 / 52$ children $(63 \%)$ continued to have plasma HIV-RNA levels lower than 50 copies $/ \mathrm{ml}$. Virological failure occurred in 12 children $(20 \%)$. No data were available for the remaining five children after reaching viral suppression. The probability of virological failure was significantly higher in children than in adults ( $p=0.03$, Fig. 3 ).

At one-year follow-up, the plasma HIV-RNA level was lower than 400 copies $/ \mathrm{ml}$ in 35 children $(35 / 66$ ITT $=53 \%$, $35 / 49 \mathrm{OT}=71 \%$ ) and lower than 50 copies $/ \mathrm{ml}$ in 30 children (30/66 ITT $=45 \%, 30 / 49$ OT $=61 \%)$.

The mean CD4\% increase was 12.6 (95\% CI: $10.4-14.8$, $p<0.001)$ at week 24 and 17.6 (95\% CI: $14.1-21.1, p<0.001)$ at week 52. The median CD4\% at week 52 was 26.3 (IQR $20.0-33.0)$. Fifty-three children $(80 \%)$ achieved a CD $4 \%$ of over 15 during the 52 weeks of follow-up and $53 \%$ of these children attained this response within six weeks.

The children also gained weight during the study: the mean weight gain was $2.2 \mathrm{~kg}(95 \% \mathrm{CI}: 1.8-2.6, p<0.001)$ at week 24 and $3.6 \mathrm{~kg}(95 \%$ CI: $3.2-4.1, p<0.001)$ at week 52 .

\section{Predictors of efficacy in adults}

A Karnofsky score $\leq 50$, a BMI in the lowest quartile $\left(<17.1 \mathrm{~kg} / \mathrm{m}^{2}\right)$, and a CD4+ T-cell count $<50 / \mathrm{mm}^{3}$ were all associated with death in the univariate analysis. In multivariate analysis, a Karnofsky score $\leq 50$ at baseline (95\% CI: $0.09-0.32, p<0.001)$ and a CD4+ T-cell count $<50 / \mathrm{mm}^{3}$ (95\% CI: $0.30-0.96, p=.04$ ) remained as independent predictors of death.

When the CD4 T-cell count remained below $200 / \mathrm{mm}^{3}$ during the year of observation, it was classified as a poor immunological response. A Karnofsky score $\leq 50$, a BMI in the lowest quartile $\left(<17.1 \mathrm{~kg} / \mathrm{m}^{2}\right)$, a CD4+ T-cell count $<50 / \mathrm{mm}^{3}$, and gender were associated with a poor immunological response in both the univariate and multivariate analyses.

A CD4+ T-cell count $<50 / \mathrm{mm}^{3}$ at baseline was also associated with a statistically significant lower chance of attaining a plasma HIV-RNA level lower than 50 copies $/ \mathrm{ml}$ $(p=0.01)$.

\section{Discussion}

This study shows the feasibility of antiretroviral treatment administered and monitored by general practitioners in a primary healthcare setting in rural South Africa.

One year after the start of HAART, 89 of 609 adults (15\%) were lost to follow-up and 113 adults had died (19\%). Patients who did not show up for their scheduled visits were actively followed-up. It seemed that patients were often lost to follow-up due to labor migration, patient preference for traditional healers, or the lack of means to visit the clinic, but the exact numbers are unknown. There is no reason to believe that a considerable number of patients who were lost to follow-up had died, as their baseline characteristics were similar to the rest of the patients, apart from the baseline CD4+ T-cell count, which was even higher in the patients who were lost to follow-up.

Immunologic outcomes were good: the mean CD4+ Tcell count increase after one year was $236 / \mathrm{mm}^{3}$; previous studies showed increases in mean CD4+ T-cell counts ranging from $127 / \mathrm{mm}^{3}$ to $165 / \mathrm{mm}^{3}[5,8-11]$.

In an on-treatment analysis at one-year follow-up, $83 \%$ of the adult patients had a plasma HIV-RNA level lower than 400 copies $/ \mathrm{ml}$ and $70 \%$ of patients had a plasma HIVRNA level lower than 50 copies $/ \mathrm{ml}$; ITT was $55 \%$ and $46 \%$, respectively. These results compare well to the results of HAART in other settings. A historical meta-analysis of clinical trials on NNRTI-based triple combination therapy in antiretroviral-naïve patients in western settings showed a plasma HIV-RNA level lower than 50 copies $/ \mathrm{ml}$ after 48 weeks of treatment in $51 \%$ of patients (ITT) [5]. An on-treatment analysis in a recent study on HAART in subSahara Africa showed a plasma HIV-RNA level lower than 50 copies $/ \mathrm{ml}$ in $61 \%$ of patients after 48 weeks of therapy (ITT 55\%) [11]. Additionally, a meta-analysis of ten studies on the efficacy of antiretroviral therapy in resource-poor, urban settings showed similar virologic responses as that observed in our study [17]. However, with the current treatment options and low pill burden, outcomes in developed countries are clearly better today $[18,19]$.

A recent comparative study examining viral suppression in resource-poor and industrialized settings states that the virologic responses are similar in these two settings when correction is applied for the increased mortality rates in the resource-poor settings during the first months of therapy [20]. In our study, high mortality rates during the first months of HAART were also observed [17, 21]. Patients often sought help at an advanced stage of their disease; a lower BMI and CD4+ T-cell count in men suggests that men deferred coming to the clinic for even longer than women. As a low Karnofsky score and a low baseline CD4+ T-cell count were both independently associated with death, this partly explains the relatively low survival outcomes in the intention-to-treat analyses and points to a need for earlier intervention.

Most studies on the virologic and immunologic efficacy of HAART in sub-Saharan Africa were performed in urban areas [6-9, 17], whereas the patients included in our study lived in a rural environment with high unemployment rates and a high HIV prevalence. This distinction is important, as people living in remote areas often miss out on proper care 
and the process of scaling-up antiretroviral therapy in such settings in sub-Saharan Africa meets different challenges $[10,22]$. A recent analysis showed that only $21 \%$ of the people in Mpumalanga estimated to be in need of HAART actually received it by the end of 2005 [23]. Apart from the difference between urban and rural settings, the sociodemographic data in our cohort (Table 1) are similar to those found in a previous study from Cape Town [24].

Virological failure occurred more often in children $(20 \%)$ than in adults $(10 \%)$. The reason for this finding is unclear and needs further evaluation. It is possible that the more complex dosing system using syrups instead of tablets has led to mistakes by caregivers, but other factors, such as specific adherence issues, may also have contributed to this trend. A recent report on fixed-dose combination antiretroviral therapy in children in resource-limited settings showed similar results to our study regarding the median CD4\% gain [25]. The median follow-up time in that study was only 6 months however, and no longitudinal viral load testing was performed.

Independent predictors of death in adults were a low Karnofsky score and a low CD4+ T-cell count at baseline. In contrast to other studies [9, 10, 26, 27], we did not find a significant correlation between low body weight and death. All of the parameters included (low CD4+ T-cell count, Karnofsky score, BMI, and gender) were independently associated with a poor immunological response. The breakdown analysis of CD4+ T-cell counts at baseline also showed a clear trend towards higher survival rates with increasing CD4+ T-cell counts (Table 2), supporting a previous study which states that initiating HAART in patients with CD4+ T-cell counts of over 200 is costeffective [28]. Another report found a low baseline CD4+ T-cell count to be predictive of a poor, virological outcome [11]; this was confirmed by our data.

Unlike many other studies on HAART programs in Africa [8-11], we measured the viral load in individual patients throughout the treatment period. In contrast to the opinion of some authors [29, 30], our data indicate that longitudinal viral load testing is possible in developing countries. In our opinion, viral load testing plays a significant role in clinical decision-making during HAART. The lack of routine viral load testing can lead to the misdiagnosis of treatment failure and may result in unnecessary regimen changes [31, 32]. An unexpected rise in plasma HIV-RNA levels can indicate poor patient adherence to treatment or viral resistance, and can be used as a criterion for extra counseling or the changing of treatment regimens.

The HAART program at the Ndlovu Medical Centre provides extensive counseling before and during treatment. Since most of the staff and all counselors are local people, some HIV-positive themselves, they are able to comprehend and discuss many problems that patients in the program encounter. Given that adherence is vital to good treatment outcomes [10, 33-35], we feel that the emphasis on counseling and adherence were essential for the program's success. However, even in this closely monitored, strictly counseled, and fully funded environment, with no monetary costs for the patient, over $15 \%$ of patients were lost to follow-up. Many domestic, social, and educational hurdles still need to be overcome in order to achieve a more favorable compliance rate.

We recognize that this study was limited by the relatively short follow-up period.

In summary, this study shows that the treatment and monitoring of HIV-infected patients by general practitioners in rural areas in sub-Saharan Africa can result in good virological, immunological, and clinical outcomes. In order to achieve even more favorable results, early mortality should be reduced and efforts should be made to start HAART at an earlier stage of disease. These data support the viability of and the need for large-scale initiatives to address the enormous threat that AIDS has become worldwide. Many questions remain unanswered, however, and future research should focus on the long-term outcomes of HAART and the possibilities for second and consecutive lines of treatment in an attempt to predict and control viral resistance.

Open Access This article is distributed under the terms of the Creative Commons Attribution Noncommercial License which permits any noncommercial use, distribution, and reproduction in any medium, provided the original author(s) and source are credited.

\section{References}

1. World Health Organization (WHO) (2004) Scaling up antiretroviral therapy in resource-limited settings: treatment guidelines for a public health approach. WHO, Geneva, Switzerland. Available online at: http://www.who.int/hiv/pub/prev_care/en/arvrevision2003en.pdf

2. Panel on clinical practices for the treatment of HIV infection, convened by the DHHS (2008) Guidelines for the use of antiretroviral agents in HIV-1-infected adults and adolescents, January 29, 2008. Available online at: http://aidsinfo.nih.gov/ ContentFiles/AdultandAdolescentGL.pdf

3. Panel on clinical practices for the treatment of HIV infection, convened by the DHHS (2008) Guidelines for the use of antiretroviral agents in pediatric HIV infection, February 28, 2008. Available online at: http://aidsinfo.nih.gov/ContentFiles/ PediatricGuidelines.pdf

4. Egger M, May M, Chêne G, Philips AN, Ledergerber B, Dabis F, Costagliola D, D'Arminio Monforte A, de Wolf F, Reiss P, Lundgren JD, Justice AC, Staszewski S, Leport C, Hogg RS, Sabin CA, Gill MJ, Salzberger B, Sterne JA; ART Cohort Collaboration (2002) Prognosis of HIV-1-infected patients starting highly active antiretroviral therapy: a collaborative analysis of prospective studies. Lancet 360:119-129 
5. Bartlett JA, DeMasi R, Quinn J, Moxham C, Rousseau F (2001) Overview of the effectiveness of triple combination therapy in antiretroviral-naïve HIV-1 infected adults. AIDS 15:1369-1377

6. Laurent C, Diakhaté N, Gueye NFN, Touré MA, Sow PS, Faye MA, Gueye M, Lanièce I, Touré Kane C, Liégeois F, Vergne L, Mboup S, Badiane S, Ndoye I, Delaporte E (2002) The Senegalese government's highly active antiretroviral therapy initiative: an 18-month follow-up study. AIDS 16:1363-1370

7. Coetzee D, Hildebrand K, Boulle A, Maartens G, Louis F, Labatala V, Reuter H, Ntwana N, Goemaere E (2004) Outcomes after two years of providing antiretroviral treatment in Khayelitsha, South Africa. AIDS 18:887-895

8. Wools-Kaloustian K, Kimaiyo S, Diero L, Siika A, Sidle J, Yiannoutsos CT, Musick B, Einterz R, Fife KH, Tierney WM (2006) Viability and effectiveness of large-scale HIV treatment initiatives in sub-Saharan Africa: experience from western Kenya. AIDS 20:41-48

9. Severe P, Leger P, Charles M, Noel F, Bonhomme G, Bois G, George E, Kenel-Pierre S, Wright PF, Gulick R, Johnson WD Jr, Pape JW, Fitzgerald DW (2005) Antiretroviral therapy in a thousand patients with AIDS in Haiti. N Engl J Med 353:2325-2334

10. Ferradini L, Jeannin A, Pinoges L, Izopet J, Odhiambo D, Mankhambo L, Karungi G, Szumilin E, Balandine S, Fedida G, Carrieri MP, Spire B, Ford N, Tassie JM, Guerin PJ, Brasher C (2006) Scaling up of highly active antiretroviral therapy in a rural district of Malawi: an effectiveness assessment. Lancet 367:1335-1342

11. DART Virology Group and Trial Team (2006) Virological response to a triple nucleoside/nucleotide analogue regimen over 48 weeks in HIV-1-infected adults in Africa. AIDS 20:1391-1399

12. World Health Organization (WHO) (2006) Progress on global access to HIV antiretroviral therapy. A report on "3by5" and beyond, March, 2006. Available online at: http://www.who.int/ hiv/fullreport_en_highres.pdf

13. Hosegood V, Vanneste AM, Timaeus IM (2004) Levels and causes of adult mortality in rural South Africa: the impact of AIDS. AIDS 18:663-671

14. Human Sciences Research Council of South Africa (2005) The South African national HIV prevalence, HIV incidence, behaviour and communication survey, 2005. Available online at: http://www. hsrc.ac.za/media/2005/11/20051130 1Factsheet2.html

15. Department of Health, Republic of South Africa (2004) National HIV and syphilis antenatal sero-prevalence survey in South Africa, 2004. Available online at: http://www.doh.gov.za/docs/ reports/2004/hiv-syphilis02.pdf

16. National Department of Health, South Africa (2004) National antiretroviral treatment guideline, 2004. Available online at: http:// hivinsite.ucsf.edu/doc/cr09-sf-01.doc

17. Ivers LC, Kendrick D, Doucette K (2005) Efficacy of antiretroviral therapy programs in resource-poor settings: a meta-analysis of the published literature. Clin Infect Dis 41:217-224

18. Gulick RM, Ribaudo HJ, Shikuma CM, Lalama C, Schackman BR, Meyer WA 3rd, Acosta EP, Schouten J, Squires KE, Pilcher CD, Murphy RL, Koletar SL, Carlson M, Reichman RC, Bastow B, Klingman KL, Kuritzkes DR; AIDS Clinical Trials Group (ACTG) A5095 Study Team (2006) Three- vs four-drug antiretroviral regimens for the initial treatment of HIV-1 infection: a randomized controlled trial. JAMA 296:769-781

19. Gallant JE, DeJesus E, Arribas JR, Pozniak AL, Gazzard B, Campo RE, Lu B, McColl D, Chuck S, Enejosa J, Toole JJ, Cheng AK (2006) Tenofovir DF, emtricitabine, and efavirenz vs. zidovudine, lamivudine, and efavirenz for HIV. N Engl J Med 354:251-260

20. ART-LINC Collaboration and ART-CC groups (2006) Mortality of HIV-1-infected patients in the first year of antiretroviral therapy: comparison between low-income and high-income countries. Lancet 367:817-824
21. van der Sande MA, Schim van Der Loeff MF, Aveika AA, Sabally S, Togun T, Sarge-Njie R, Alabi AS, Jaye A, Corrah T, Whittle HC (2004) Body mass index at time of HIV diagnosis: a strong and independent predictor of survival. J Acquir Immune Defic Syndr 37:1288-1294

22. Van Damme W, Kober K, Laga M (2006) The real challenges for scaling up ART in sub-Saharan Africa. AIDS 20:653-656

23. Nattrass N (2006) South Africa's "rollout" of highly active antiretroviral therapy: a critical assessment. J Acquir Immune Defic Syndr 43:618-623

24. Coetzee C, Nattrass N (2004) Living on AIDS treatment: a socioeconomic profile of Africans receiving antiretroviral therapy in Khayelitsha, Cape Town. CSSR Working paper no. 04/071. Available online at: http://www.cssr.uct.ac.za/pubs_cssr.asp

25. O'Brien DP, Sauvageot D, Zachariah R, Humblet P; Medecins Sans Frontieres (2006) In resource-limited settings good early outcomes can be achieved in children using adult fixed-dose combination antiretroviral therapy. AIDS 20:1955-1960

26. Chan KC, Yip B, Hogg RS, Montaner JS, O’Shaughnessy MV (2002) Survival rates after the initiation of antiretroviral therapy stratified by CD4 cell counts in two cohorts in Canada and the United States. AIDS 16:1693-1695

27. Erikstrup C, Kallestrup P, Zinyama R, Gomo E, Mudenge B, Gerstoft J, Ullum H (2007) Predictors of mortality in a cohort of HIV-1-infected adults in rural Africa. J Acquir Immune Defic Syndr 44(4):478-483

28. Badri M, Cleary S, Maartens G, Pitt J, Bekker LG, Orrell C, Wood R (2006) When to initiate highly active antiretroviral therapy in sub-Saharan Africa? A South African cost-effectiveness study. Antivir Ther 11:63-72

29. Koenig SP, Kuritzkes DR, Hirsch MS, Léandre F, Mukherjee JS, Farmer PE, del Rio C (2006) Monitoring HIV treatment in developing countries. BMJ 332:602-604

30. Colebunders R, Moses KR, Laurence J, Shihab HM, Semitala F, Lutwama F, Bakeera-Kitaka S, Lynen L, Spacek L, Reynolds SJ, Quinn TC, Viner B, Mayanja-Kizza H (2006) A new model to monitor the virological efficacy of antiretroviral treatment in resource-poor countries. Lancet Infect Dis 6:53-59

31. Basenero A, Castelnuovo B, Birabwa E, John L, MacAdam K, Schlech W, Kambugu A (2007) Inadequacy of clinical and immunological criteria in identifying virologic failure of 1 st line ART: the Ugandan experience. In: Program and abstracts of the 4th International Aids Society (IAS) Conference on HIV Pathogenesis, Treatment and Prevention, Sydney, Australia July, 2007, abstract WEAB102

32. Hosseinipour $M$, van Oosterhout $J$, Weigel $R$, Mzigangira D, Saukila N, Mhango B, Phiri R, Phiri S, Kumwenda J (2007) Validating clinical and immunological definitions of antiretroviral treatment failure in Malawi. In: Program and abstracts of the 4th International Aids Society (IAS) Conference on HIV Pathogenesis, Treatment and Prevention, Sydney, Australia, July 2007, abstract WEAB101

33. Mannheimer S, Friedland G, Matts J, Child C, Chesney M (2002) The consistency of adherence to antiretroviral therapy predicts biologic outcomes for human immunodeficiency virus-infected persons in clinical trials. Clin Infect Dis 34:1115-1121

34. Osterberg L, Blaschke T (2005) Adherence to medication. N Engl J Med 353:487-497

35. Mills EJ, Nachega JB, Buchan I, Orbinski J, Attaran A, Singh S, Rachlis B, Wu P, Cooper C, Thabane L, Wilson K, Guyatt GH, Bangsberg DR (2006) Adherence to antiretroviral therapy in subSaharan Africa and North America: a meta-analysis. JAMA 296:679-690 